\title{
Correlation between Pathogenicity and Temperature Sensitivity in Different Strains of Histoplasma capsulatum
}

\author{
Gerald Medoff," Bruno Maresca,‡ Alan M. Lambowitz,\$ George Kobayashi,* \\ Audrey Painter," Margherita Sacco, $\neq$ and Luisella Carratuł \\ *Infectious Disease Division and the Divisions of Dermatology and of Laboratory Medicine, Departments of Medicine, Microbiology, and \\ Immunology, Washington University School of Medicine, St. Louis, Missouri 63110; †Istituto Internazionale di Genetica e Biofisica, \\ Naples, Italy; and §Departments of Genetics and Biochemistry, The Ohio State University, Columbus, Ohio 43210
}

\begin{abstract}
We compared the mycelial to yeast transitions of the Downs strain of Histoplasma capsulatum (low level of virulence) with those of G184A and G222B, two more virulent strains having different levels of pathogenicity for mice. When the morphological transitions are initiated by a temperature shift from $25^{\circ}$ to $37^{\circ} \mathrm{C}$, all three strains undergo similar physiological changes, but these are less severe in G184A and G222B than in the Downs strain. The transitions from mycelial to yeast morphology in both of the more virulent strains are also one-third more rapid than in Downs. We also find that the differences in temperature sensitivity of the three strains can be correlated with the temperature required for complete uncoupling of oxidative phosphorylation. The differences in sensitivity to elevated temperatures extend to the growth of yeast cells of all three strains.

Considered together, our results suggest that sensitivity to elevated temperatures may be a key factor accounting for differences in virulence and that uncoupling of oxidative phosphorylation may be the primary event in the morphological transition in all three strains.
\end{abstract}

\section{Introduction}

Histoplasma capsulatum is a dimorphic fungal pathogen that grows as a multicellular mycelium in soil and as a unicellular yeast in the reticuloendothelial cells of infected humans and animals (1). The morphogenic process and the factors that affect it are of considerable interest, because growth of the yeast phase appears to be required for pathogenicity (2).

We have studied the transition from mycelial to yeast morphology in the Downs strain of $H$. capsulatum, a clinical isolate that has been passaged continuously in our laboratory for $\sim 13$ yr (3). In culture, the mycelial to yeast transition can be triggered by a shift in temperature from $25^{\circ}$ to $37^{\circ} \mathrm{C}$. Three distinct stages in the morphological transition have been delineated (4). Stage 1 , immediately after the temperature shift, is characterized by uncoupling of oxidative phosphorylation and a rapid decline in ATP levels. Over the next $24 \mathrm{~h}$, there is a progressive decrease in respiration rate, and in the rates of RNA and protein synthesis.

Address correspondence to Dr. Medoff, Washington U. School of Medicine, Infectious Disease Div., Department of Medicine, Box 8051, St. Louis, MO 63110.

Received for publication 19 August 1985 and in revised form 11 August 1986.

J. Clin. Invest.

(C) The American Society for Clinical Investigation, Inc.

$0021-9738 / 86 / 12 / 1638 / 10 \quad \$ 1.00$

Volume 78, December 1986, 1638-1647
After 24 to $40 \mathrm{~h}$, the cells enter a dormant period (stage 2) that lasts 4-6 d. Stage 2 cells are characterized by very low rates of respiration, grossly decreased concentrations of mitochondrial electron transport components, and strong inhibition of RNA and protein synthesis. Exogenous cysteine or other sulfhydrylcontaining compounds are required during stage 2 to rectivate mitochondrial respiration via shunt pathways that bypass inhibited portions of the electron transport system (5). Stage 3 is characterized by increasing concentrations of cytochrome components, resumption of normal respiration, induction of the yeast phase-specific cysteine oxidase, and completion of the transition to yeast morphology $(4,6)$.

The Downs strain of $H$. capsulatum is an attenuated variety (reference 7; $\mathrm{LD}_{50}$ for $\mathrm{AKR}$ mice $7 \mathrm{~d}$ after infection is $20-22$ $\times 10^{6}$ yeast per $\mathrm{ml}$ ). Initial experiments on several more virulent $H$. capsulatum strains (G184A, G186A, G217B, and G222B; $\mathrm{LD}_{50}$ values for $\mathrm{AKR}$ mice are 0.5-9.0 $\times 10^{6}$ yeast per $\mathrm{ml}$ ) showed that the $25^{\circ}$ to $37^{\circ} \mathrm{C}$ temperature shift resulted in only a transitory decline in ATP levels to $\sim 50 \%$ of those of control cells at $25^{\circ} \mathrm{C}(7)$.

In the present work, we carried out more detailed studies of the morphological transition of two more virulent strains (G184A, $L_{50}$ for AKR mice $7 \mathrm{~d}$ after infection is $9 \times 10^{6}$ yeast per $\mathrm{ml}$; and $\mathrm{G} 222 \mathrm{~B}, \mathrm{LD}_{50}$ is $6 \times 10^{6}$ yeast per $\mathrm{ml}$ ). These studies showed that the mycelial to yeast transitions induced by a temperature shift from $25^{\circ}$ to $37^{\circ} \mathrm{C}$ are similar to that of the Downs strain, but the changes are less extreme. Respiration was only partially uncoupled from oxidative phosphorylation, the decline in ATP levels was transitory, and respiration rates decreased to a lesser extent than in the Downs strains. Concentrations of cytochrome components fell to $11-38 \%$ of initial values, but they remained detectable throughout the transition. There was no distinct dormant phase, and the transition of both of the more virulent strains to yeast morphology was one-third more rapid than in the Downs strain. The changes in respiration and ATP levels were more marked in G184A than in G222B. Considered together, these results are consistent with the idea that a heat-related insult triggers the morphological transition in all three strains, and that pathogenicity is correlated with their sensitivity to elevated temperature. Similarly, the prolonged dormant phase of the Downs strain (stage 2) may reflect a greater sensitivity to temperature shifts compared with other strains.

These hypotheses were tested further by examining the mycelial to yeast transition of the Downs strain at $34^{\circ} \mathrm{C}$ and the two more virulent isolates at $40^{\circ}$ to $43^{\circ} \mathrm{C}$. The physiological changes during the morphologic mycelial to yeast transition of Downs at $34^{\circ} \mathrm{C}$ were similar to those of the more virulent strains at $37^{\circ} \mathrm{C}$; conversely, when the more virulent strains were shifted to temperatures of $40^{\circ}$ to $43^{\circ} \mathrm{C}$, their mycelial to yeast transitions were similar to that of Downs at $37^{\circ} \mathrm{C}$. As before, G184A ap- 
peared to be more temperature sensitive than the more virulent G222B.

Finally, the sensitivity to elevated temperatures extended to the yeast phase of all three strains. At $35^{\circ} \mathrm{C}$, growth of Downs, $\mathrm{G} 184 \mathrm{~A}$, and $\mathrm{G} 222 \mathrm{~B}$ yeast cells was indistinguishable. At $37^{\circ} \mathrm{C}$, Downs yeast cells showed a significant lag phase compared with G184A and G222B yeast cells, and the growth rate was also slower in Downs. At $39^{\circ} \mathrm{C}$, the lag phase in Downs was longer, the growth rate less, and a lower growth yield was apparent, compared with G184A and G222B. At $41^{\circ} \mathrm{C}$, Downs did not grow at all. G222B and G184A still showed residual growth at $41^{\circ} \mathrm{C}$ and the rate of growth and yields were higher in cultures of G222B than G184A. Based on these results, we hypothesize that temperature sensitivity is a key factor accounting for the differences in virulence of these three strains of $\boldsymbol{H}$. capsulatum and that uncoupling of oxidative phosphorylation is the trigerring event in the mycelial to yeast transition of all three strains.

\section{Methods}

Strains. The Downs strain of $H$. capsulatum is a clinical isolate that has been passaged in our laboratory for $\sim 13 \mathrm{yr}$ (3). The G184A and G222B strains of $H$. capsulatum were originally obtained from the American Type Culture Collection (Rockville, MD).

Culture conditions. Cells were grown in $2 \%$ glucose, $1 \%$ yeast extract as described previously (5). Cultures were started with a constant inoculum of cells and were grown to midlog phase, which occurred after 48 to $72 \mathrm{~h}$ of incubation at $25^{\circ} \mathrm{C}$ for mycelia and $37^{\circ} \mathrm{C}$ for yeast. Growth of yeast cells in the liquid culture was monitored turbidimetrically by measuring absorbance at $650 \mathrm{~nm}$ in 18-mm culture tubes in a Bausch and Lomb spectronic 20 spectrophotometer. Absorbance values were correlated with cell number counted in a Levy-Hauser cell-counting chamber. In the experiments on transforming cells, mycelial cultures were diluted 1:5 in fresh medium, divided among several flasks, and incubated at the higher temperatures, which ranged from $34^{\circ}$ to $43^{\circ} \mathrm{C}$. The flasks were harvested at different times, and respiration rates were measured. Other portions of the cultures were filtered and dried at $42^{\circ} \mathrm{C}$ to determine dry weights.

Determination of virulence. The lethality of the three strains of $H$. capsulatum for AKR mice was determined by the number of deaths after tail vein injection of $0.2-\mathrm{ml}$ suspensions of graded doses of viable yeast or early germinated mycelia $\left(1 \times 10^{5}\right.$ to $1 \times 10^{7}$ cells per $\left.\mathrm{ml}\right)$ in phosphatebuffered saline. Early germination of mycelia was documented microscopically and the cultures were used when $90 \%$ of the fungi had germ tubes that were at least twice the diameter of the yeast cells. Cell suspensions for infection were quantitated using a cell-counting chamber and the numbers of viable cells were determined by colony counts on brain heart infusion agar (Difco Laboratories, Detroit, MI) that was supplemented with growth factor and cysteine by the procedure of Burt et al. (8). There were 10 mice in each dose group. The lowest inocula of $H$. capsulatum cells, which killed $50 \%$ of the mice within a week of infection $\left(\mathrm{LD}_{50}\right)$, were determined by probit analyses (9).

The $\mathrm{LD}_{50}$ value of the Downs strain for mice is $20 \times 10^{6}$ yeast per $\mathrm{ml}$; values for G184A and G222B are $9 \times 10^{6}$ and $6 \times 10^{6}$ yeast cells per $\mathrm{ml}$, respectively. $\mathrm{LD}_{50}$ values of early germinated mycelia were essentially the same as those of yeast.

Reagents. Oligomycin and carbonyl cyanide $m$-chlorophenylhydrazone $(\mathrm{Cl}-\mathrm{CCP})^{1}$ were obtained from Sigma Chemical Co. (St. Louis, MO) and were dissolved in absolute ethanol just before use. Ethanol, at the concentrations used in these experiments, had no effect on oxygen uptake.

1. Abbreviations used in this paper: $\mathrm{Cl}-\mathrm{CCP}$, carbonyl cyanide $m$-chlorophenylhydrazone; SHAM, salicylhydroxamic acid.
Isolation of mitochondria. Yeast, mycelia, and cells at intermediate stages of the morphological transition were isolated by filtration through No. 1 filter paper (Whatman Laboratory Products Inc., Whatman Paper Div., Clifton, NJ), washed with distilled cold water, and resuspended in $0.33 \mathrm{M}$ sucrose, $1 \mathrm{mM}$ ethylene glycol bis- $N, N^{\prime}$-tetraacetic acid, $\mathrm{pH} 7.0$, and $0.3 \%$ bovine serum albumin. Glass beads, one-third volume, were added, and the cells were broken by three 15-s bursts in a Braun cell homogenizer (model MSK; Fisher Scientific Co., St. Louis, MO) and cooled intermittently with liquid $\mathrm{CO}_{2}$. The homogenate was centrifuged twice at $800 \mathrm{~g}(10 \mathrm{~min})$ and the mitochondria were pelleted at $17,000 \mathrm{~g}$ (30 min). The mitochondrial pellets were resuspended in mitochondrial respiration buffer consisting of $0.3 \mathrm{M}$ sucrose, $8 \mathrm{mM} \mathrm{NaH}_{2} \mathrm{PO}_{4}, 5 \mathrm{mM}$ $\mathrm{MgCl}_{2}, 1 \mathrm{mM}$ ethylenediaminetetraacetic acid (EDTA), and $8 \mathrm{mM}$ Tris$\mathrm{HCl}, \mathrm{pH} 7.2$.

Measurements of oxygen consumption. Cells were suspended in cell respiration buffer containing $1 \%$ mannose, $1 \mathrm{mM} \mathrm{CaCl}_{2}$, and $1 \mathrm{mM}$ dimethylglutaric acid ( $\mathrm{pH}$ 7.2). Oxygen concentration was measured polarographically using a KIC oxygraph equipped with a Clark-type oxygen electrode (Gilson Instruments, Middleton, WI). Cell respiration rates were expressed as microliters of $\mathrm{O}_{2}$ per hour per milligram dry weight of cells.

Coupling of oxidative phosphorylation. Coupling of oxidative phosphorylation was assayed by the ability of an uncoupler (Cl-CCP) to stimulate respiration in the presence of oligomycin, an inhibitor of ATP synthetase (7). Cell respiration assays were carried out in the presence of salicylhydroxamic acid (SHAM) to inhibit the alternate oxidase and force electron flux through the cytochrome system (10).

Spectrophotometric measurements. Spectrophotometric measurements were carried out with an Aminco-DW2 dual and wavelength spectrophotometer (5). The cuvette used for low temperature spectra $\left(77^{\circ} \mathrm{K}\right)$ had a path length of $1 \mathrm{~mm}$, and the cuvette used for room temperature spectra had a path length of $1 \mathrm{~cm}$. Mitochondria were suspended in 0.3 $\mathrm{M}$ sucrose, $8 \mathrm{mM} \mathrm{NaH}_{2} \mathrm{PO}_{4}, 8 \mathrm{mM}$ Tris, $\mathrm{pH} 7.2$, and $1 \mathrm{mM}$ EDTA.

Measurement of ATP levels. Cells were collected by rapid filtration and immediately frozen in liquid $\mathrm{N}_{2}$. ATP was extracted with perchlorate and assayed by the glucose-6-phosphate dehydrogenase/hexokinase method (11). Each assay used 10-15 mg dry weight of cells. ATP concentrations were expressed as micromoles ATP per gram dry weight.

Protein measurements. Proteins were measured by the Lowry method (12).

\section{Results}

\section{Physiological changes during the mycelial to yeast transition induced by a temperature shift from $25^{\circ}$ to $37^{\circ} \mathrm{C}$}

In previous work, we characterized physiological changes during the mycelial to yeast transition of the Downs strain of $H$. capsulatum induced by a temperature shift from $25^{\circ}$ to $37^{\circ} \mathrm{C}(4$, $5,7)$. The same temperature shift is sufficient to induce the morphological transition of the more virulent G184A and G222B strains of $H$. capsulatum. We began the present study by comparing physiological changes in these virulent strains with those in Downs after temperature shift from $25^{\circ}$ to $37^{\circ} \mathrm{C}$. We found the same pattern of physiological changes, but the responses were muted in the more virulent strains.

Uncoupling of respiration. Fig. 1 compares the effect of a temperature shift from $25^{\circ}$ to $37^{\circ} \mathrm{C}$ on respiration in the mycelia of the Downs strain and more virulent strains, G184A and G222B. Coupling between respiration and oxidative phosphorylation in whole cells was assayed by the ability of the uncoupler $\mathrm{Cl}-\mathrm{CCP}$ to stimulate respiration in the presence of oligomycin, an inhibitor of ATP synthetase. Stimulation of respiration by $\mathrm{Cl}-\mathrm{CCP}$ indicates that respiration was coupled to ATP synthesis, whereas lack of stimulation indicates uncoupled respiration (13, 14). The respiration measurements were carried out in the pres- 


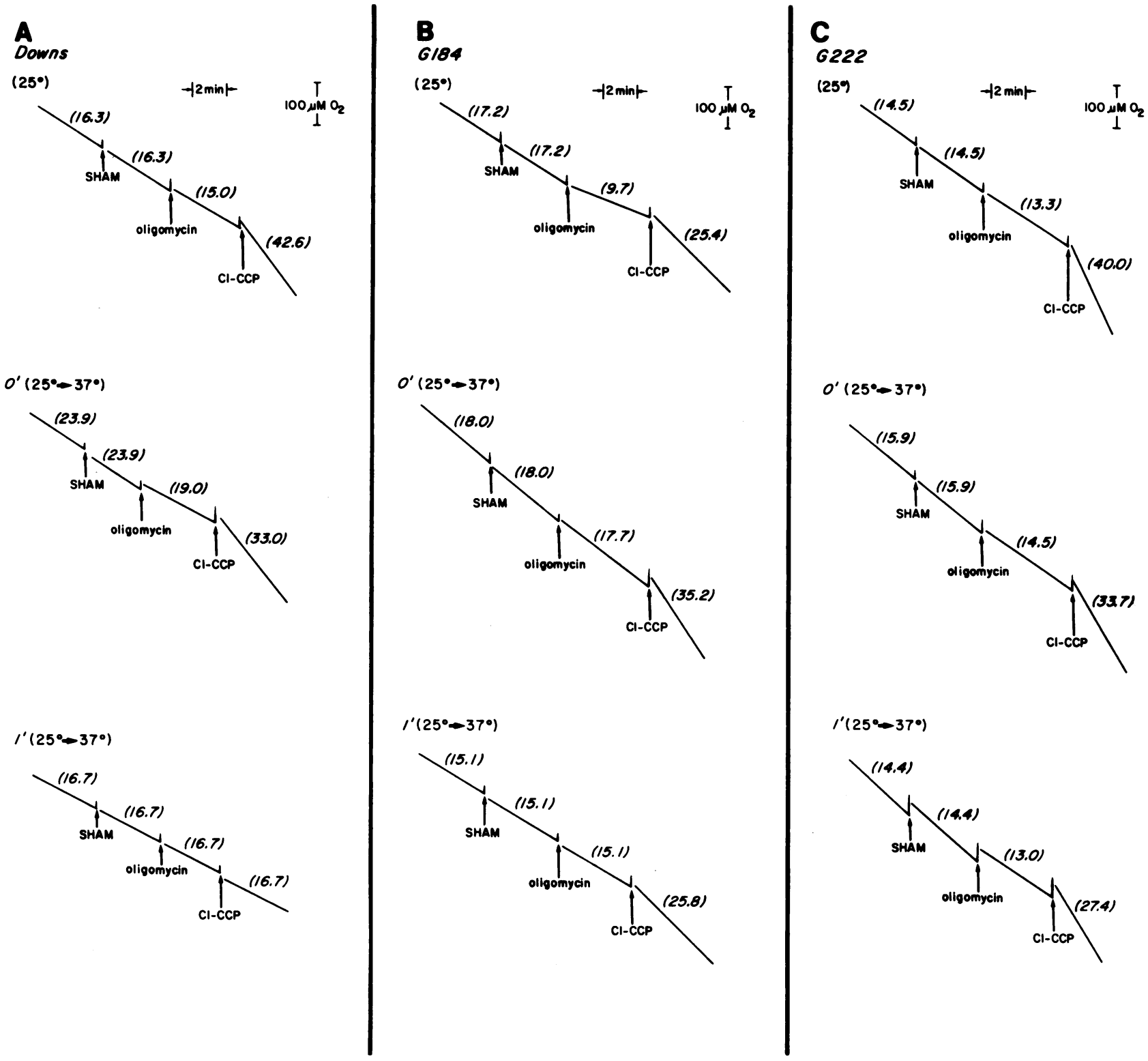

Figure 1. Oxygen electrode recordings of respiration of mycelial cells at $25^{\circ} \mathrm{C}$, immediately after (0) and $1 \mathrm{~min}$ after shift up to $37^{\circ} \mathrm{C}$. To initiate the experiments, $0.5 \mathrm{ml}$ of cultures in $10-\mathrm{ml}$ tubes were switched from one water bath at $25^{\circ} \mathrm{C}$ to another at $37^{\circ} \mathrm{C}$. 3-ml portions were then added to the cuvette in the oxygraph at the designated time points. $(A)$ Downs; $(B) \mathrm{G} 184 \mathrm{~A}$; and $(C) \mathrm{G} 222 \mathrm{~B}$. The values in

ence of SHAM, an inhibitor of alternate oxidase activity (10), to force all the electron flow through the cytochrome system. Fig. $1 \mathrm{~A}$ shows respiration in the Downs strain at $25^{\circ} \mathrm{C}$, and at zero time and $1 \mathrm{~min}$ after a temperature shift from $25^{\circ}$ to $37^{\circ} \mathrm{C}$. Respiration is tightly coupled at $25^{\circ} \mathrm{C}$ (about a 2.8 -fold stimulation of respiration by $\mathrm{Cl}-\mathrm{CCP}$ ) and is rapidly uncoupled after the temperature shift up (no stimulation by $\mathrm{Cl}-\mathrm{CCP}$ within 1 min after the shift up in temperature).

Similar experiments for G184A and G222B show that respiration in these strains remains coupled to oxidative phosphorylation after the temperature shift from $25^{\circ}$ to $37^{\circ} \mathrm{C}$ (Fig. $1, B$ and $C$ ). However, the degree of stimulation by Cl-CCP is decreased in both strains, from 2.6 before the temperature shift to 1.7-fold after the temperature shift in G184A, and from 3.0 parentheses are rates of oxygen consumption ( $\mu \mathrm{l}$ of $\mathrm{O}_{2}$ per hour per milligram dry weight). Additions were oligomycin $(5 \mu \mathrm{g} / \mathrm{ml})$ and $\mathrm{Cl}-$ CCP $(0.5 \mathrm{mM})$. Salicylhydroxamic acid $(0.2 \mathrm{mM})$ was added to inhibit the alternate oxidase. The experiment was repeated six times with independent cultures and essentially identical results were obtained.

before the temperature shift to 2.1-fold after the temperature shift in G222B. This decreased stimulation by Cl-CCP suggests that partial uncoupling may have occurred. The respiration experiments for the Downs, G184A, and G222B strains were repeated on six independent cell cultures of each strain with essentially the same results.

ATP levels. The less severe effect of temperature shift on coupling of oxidative phosphorylation in the more virulent strains was paralleled by less severe effects on ATP levels. Fig. 2 shows that intracellular ATP levels drop rapidly to zero in the Downs strain after the temperature shift, whereas intracellular ATP levels in G184A and G222B fall to 29 and $43 \%$ of the initial levels, respectively, and then recover to almost preshift levels in $60 \mathrm{~min}$. 


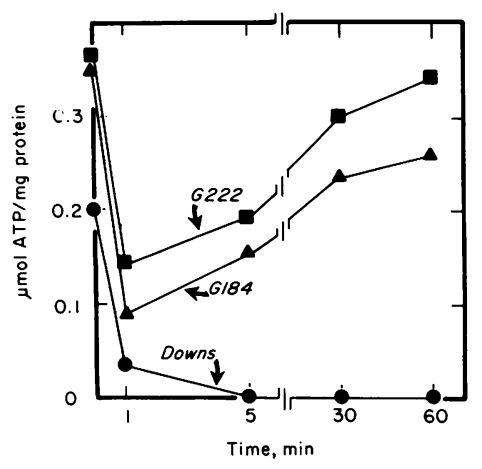

Figure 2. Effect of temperature shifts from $25^{\circ}$ to $37^{\circ} \mathrm{C}$ on intracellular ATP levels. To initiate the experiment, $10 \mathrm{ml}$ of cultures in 50-ml Erlenmeyer flasks were switched from one water bath at $25^{\circ} \mathrm{C}$ to another at $37^{\circ} \mathrm{C}$. The experiment was carried out with three independent cultures and essentially identical results were obtained.

Respiration rates. Fig. 3 shows respiration rates in the Downs strains, as a function of time after a temperature shift from $25^{\circ}$ to $37^{\circ} \mathrm{C}$. In these experiments, we were able to discern a very transient increase in respiration immediately after the shift to $37^{\circ} \mathrm{C}$ followed by the progressive decline, characteristic of stage 1 of the transition. This decline continued for $\sim 24 \mathrm{~h}$, at which time cell respiration rates were essentially zero. The dormant period (stage 2 ) lasted $\sim 5 \mathrm{~d}$, after which the cells entered stage 3 , which was characterized by a resumption of respiration and growth of yeast phase cells. Yeast forms began to appear in the Downs culture at $\sim 8-10 \mathrm{~d}$ when respiration rates were increasing, and the cultures were predominantly yeast by 12-13 d.

As in the case of ATP levels, the changes in respiration rates during the transition of G184A and G222B were less pronounced than in the Downs strain. Although the same three stages can be distinguished, the rate at which respiration decreased during stage 1 was less precipitous in the more virulent strains, and spontaneous respiration in G184A and G222B only declined to 46 and $56 \%$ of the initial levels, respectively. In addition, the morphologic transitions were more rapid in these stains than in Downs. Yeast forms appeared in the cultures by 6-7 $\mathrm{d}$ after the temperature shift, concomitant with the increase in respiration rates, and by $8-9 \mathrm{~d}$ the cultures were predominantly yeast.

Electron transport components. We previously showed that the decline in respiration in the Downs strain reflects decreased

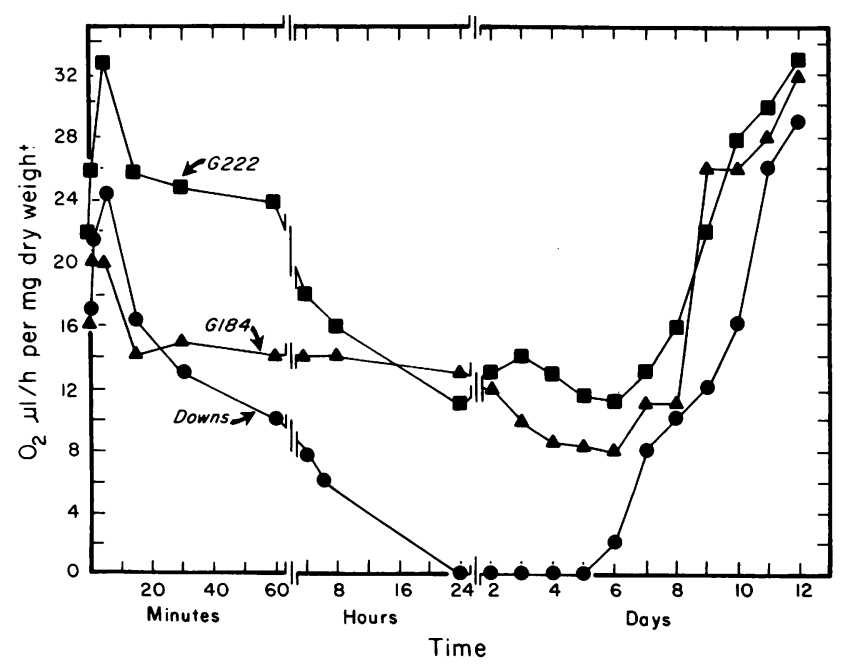

Figure 3. Respiration rates during the mycelial to yeast transition. The experiment was initiated by shifting mycelia $(10-\mathrm{ml}$ cultures in $50-\mathrm{ml}$ Erlenmeyer flasks) from $25^{\circ}$ to $37^{\circ} \mathrm{C}$. Respiration was measured both in respiration buffer and fresh medium, with essentially identical results. concentrations of electron transport components assayed spectrophotometrically. Similar changes occurred in G184A and G222B, but again, the changes were moderated compared to the Downs strain.

Fig. 4 shows $77^{\circ} \mathrm{K}$ difference spectra (succinate-reduced minus oxidized- and dithionite-reduced minus oxidized) of mitochondria from the mycelial phases of the Downs (Fig. $4 A$ ), G184A (Fig. 4 B), and G222B (Fig. 4 C) strains of $H$. capsulatum. The spectra for all three strains show alpha peaks corresponding to cytochrome $c(550 \mathrm{~nm})$, cytochrome $b(558 \mathrm{~nm})$, and cytochrome $a a_{3}(605 \mathrm{~nm})$. The spectra for G222B and Downs show an additional peak at $555 \mathrm{~nm}$, which in the Downs strain was previously assigned to cytochrome $c_{1}$. This component is probably obscured by other peaks in the spectra for G184A. In all three strains, addition of dithionite causes additional reduction of $b$-type cytochromes, as noted previously in the Downs strain (5). The spectra also show beta peaks at 510-525 nm and Soret peaks for cytochrome $b(423 \mathrm{~nm})$ and $a a_{3}(443 \mathrm{~nm})$. The Soret peak for cytochrome $c$, which is expected to appear at $\sim 418$ $\mathrm{nm}$, is presumably obscured by the Soret peak for cytochrome $b$. The trough at $\sim 465 \mathrm{~nm}$ is due to flavoproteins.

The remaining spectra in Fig. 4 show the effect of temperature shift on electron transport components in the three strains. Table I summarizes the content of electron transport components of mycelia and at different times after the shift up in temperature. In Downs (Fig. $4 \mathrm{~A}$ ), the concentrations of electron transport components decline markedly over the first $24 \mathrm{~h}$ after the temperature shift. After 1 to $2 \mathrm{~d}$, cytochromes $c$ and $a a_{3}$ are virtually undetectable, and cytochrome $b$ has decreased to approximately one-seventh of the initial level. The residual cytochrome $b$ is not reduced by succinate, which suggests that it is inactive in respiration. The minimum concentration of electron transport components occurs at $\sim 5 \mathrm{~d}$ after the temperature shift. After that, the concentrations of cytochrome components and flavoproteins increase to normal levels as yeasts begin to appear in the cultures, and the transition is completed by $12-13 \mathrm{~d}$.

Fig. 4, $B$ and $C$, show that G184A and G222B undergo similar but less extreme changes. After 1 to $2 \mathrm{~d}$, concentrations of cytochromes $a a_{3}, b$, and $c$ in G184A and G222B fall to 11-38\% of initial levels, but they remain detectable throughout the transitions. The minimum level of cytochrome components in both stains is reached after 1 to $5 \mathrm{~d}$. Cytochrome concentrations then increase as the morphological transitions proceed. Yeast cells first appear in the cultures on day 6, and the cultures are predominantly yeast by day 8 , as cytochrome concentrations approach those of normal yeast.

\section{Physiological changes during the mycelial to yeast transition induced by a temperature shift from $25^{\circ}$ to $34^{\circ}$ to $43^{\circ} \mathrm{C}$}

The preceeding results show that the patterns of physiological changes during the mycelial to yeast transitions in Downs, $\mathrm{G} 184 \mathrm{~A}$, and G222B induced by temperature shift from $25^{\circ}$ to $37^{\circ} \mathrm{C}$ are qualitatively similar, but they are more extreme in Downs than in G184A and G222B. One possible explanation is that Downs is simply more sensitive to elevated temperatures than G184A and G222B. To test this hypothesis, we studied the morphological transitions induced by shifting Downs from $25^{\circ}$ to $34^{\circ} \mathrm{C}$ and mycelia of G184A and G222B from $25^{\circ}$ to $40^{\circ}$ or $43^{\circ} \mathrm{C}$.

Uncoupling of respiration. Fig. 5 shows oxygen electrode recordings of respiration of Downs, G184A, and G222B after var- 

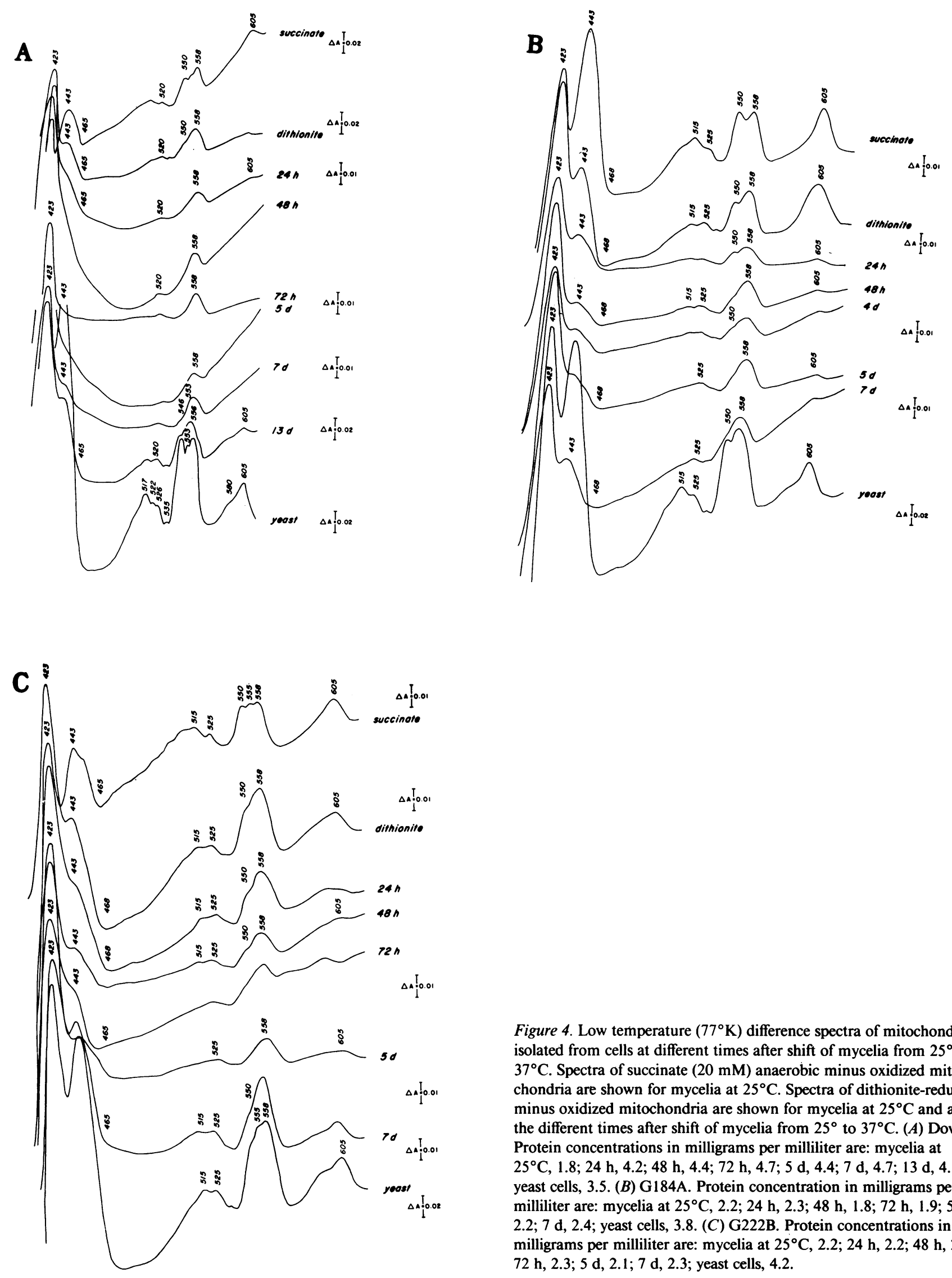

Figure 4. Low temperature $\left(77^{\circ} \mathrm{K}\right)$ difference spectra of mitochondria isolated from cells at different times after shift of mycelia from $25^{\circ}$ to $37^{\circ} \mathrm{C}$. Spectra of succinate $(20 \mathrm{mM})$ anaerobic minus oxidized mitochondria are shown for mycelia at $25^{\circ} \mathrm{C}$. Spectra of dithionite-reduced minus oxidized mitochondria are shown for mycelia at $25^{\circ} \mathrm{C}$ and at the different times after shift of mycelia from $25^{\circ}$ to $37^{\circ} \mathrm{C}$. $(A)$ Downs. Protein concentrations in milligrams per milliliter are: mycelia at $25^{\circ} \mathrm{C}, 1.8 ; 24$ h, $4.2 ; 48$ h, 4.4; 72 h, 4.7; 5 d, 4.4; 7 d, 4.7; 13 d, 4.1; yeast cells, 3.5. $(B) \mathrm{G} 184 \mathrm{~A}$. Protein concentration in milligrams per milliliter are: mycelia at $25^{\circ} \mathrm{C}, 2.2 ; 24 \mathrm{~h}, 2.3 ; 48 \mathrm{~h}, 1.8 ; 72 \mathrm{~h}, 1.9 ; 5 \mathrm{~d}$, 2.2; $7 \mathrm{~d}, 2.4$; yeast cells, 3.8. (C) G222B. Protein concentrations in milligrams per milliliter are: mycelia at $25^{\circ} \mathrm{C}, 2.2 ; 24 \mathrm{~h}, 2.2 ; 48 \mathrm{~h}, 2.2$; $72 \mathrm{~h}, 2.3 ; 5 \mathrm{~d}, 2.1 ; 7 \mathrm{~d}, 2.3$; yeast cells, 4.2 . 
Table I. Concentrations of Cytochromes in Mitochondria Isolated from Transforming Cells after a Temperature Shift from $25^{\circ}-37^{\circ} \mathrm{C}^{*}$

\begin{tabular}{|c|c|c|c|c|c|c|c|c|c|}
\hline \multirow[b]{2}{*}{ Days } & \multicolumn{3}{|l|}{ Downs } & \multicolumn{3}{|l|}{ G184A } & \multicolumn{3}{|l|}{ G222B } \\
\hline & cyt $a a_{3}$ & cyt $b$ & cyt $c$ & cyt $a a_{3}$ & cyt $b$ & cyt $c$ & cyt $a a_{3}$ & cyt $b$ & cyt $c$ \\
\hline 0 & 0.16 & 0.28 & 0.28 & 0.28 & 0.27 & 0.23 & 0.16 & 0.21 & 0.15 \\
\hline 1 & ND $\ddagger$ & 0.11 & 0.04 & 0.04 & 0.09 & 0.08 & 0.08 & 0.16 & 0.12 \\
\hline 2 & ND & 0.06 & ND & 0.04 & 0.12 & 0.10 & 0.06 & 0.10 & 0.07 \\
\hline 3 & ND & 0.06 & ND & 0.03 & 0.10 & 0.08 & 0.04 & 0.08 & 0.05 \\
\hline 5 & ND & 0.04 & ND & 0.04 & 0.13 & 0.11 & 0.05 & 0.09 & 0.05 \\
\hline 7 & ND & 0.07 & ND & 0.06 & 0.16 & 0.13 & 0.15 & 0.23 & 0.15 \\
\hline 9 & ND & 0.06 & ND & & & & & & \\
\hline 12 & ND & 0.12 & 0.08 & & & & & & \\
\hline 13 & 0.06 & 0.18 & 0.12 & & & & & & \\
\hline Yeast & 0.24 & 0.19 & 0.15 & 0.24 & 0.20 & 0.21 & 0.23 & 0.20 & 0.18 \\
\hline
\end{tabular}

cyt, cytochrome. ${ }^{*}$ Cytochrome concentrations were calculated from low temperature difference spectra of dithionite-reduced minus oxidized mitochondria. The values are expressed as nanomoles per milligram mitochondrial protein. $\ddagger N D$, nondetectable.

ious temperature shifts. Fig. $5 A$ shows that shifting the Downs strain from $25^{\circ}$ to $34^{\circ} \mathrm{C}$, which is still sufficient to induce the morphological transition, and does not result in complete uncoupling of oxidative phosphorylation, judged by stimulation of respiration by addition of the uncoupler Cl-CCP. However, respiration does appear to be partially uncoupled, as the stimulation by $\mathrm{Cl}-\mathrm{CCP}$ decreased from 2.6-fold before the temperature shift to 1.8 -fold $1 \mathrm{~min}$ after the temperature shift. At the same time, Fig. 5, $B$ and $C$, show that respiration in G184A and $\mathrm{G} 222 \mathrm{~B}$ is completely uncoupled after shifts to the higher temperatures of $41^{\circ}$ and $43^{\circ} \mathrm{C}$, respectively. This experiment was repeated at least six times on separate cultures with essentially the same results.

ATP levels. Fig. 6 shows the effects of different temperature shifts on ATP levels in the three strains. In the case of Downs, the shift to $34^{\circ} \mathrm{C}$ results in a less severe decline in ATP levels than the shift to $37^{\circ} \mathrm{C}$, which is consistent with the finding that respiration is not completely uncoupled by the shift to $34^{\circ} \mathrm{C}$ (Fig. $6 \mathrm{~A}$ ). This change in ATP levels more closely resembles those in the more virulent strains shifted to $37^{\circ} \mathrm{C}$ (Fig. 6, dashed lines).

In the case of G184A and G222B, the shift to a higher temperature $\left(40^{\circ} \mathrm{C}\right)$ results in a faster and deeper decline in ATP levels than the shift to $37^{\circ} \mathrm{C}$ (Fig. $6 \mathrm{~B}$ ). The data show that ATP levels fall to $10 \%$ of the initial values in $\mathrm{G} 184 \mathrm{~A}$ and $30 \%$ in G222B. The ATP levels remain depressed for at least $60 \mathrm{~min}$. These changes in ATP levels more closely resemble those in the Downs strain shifted to $37^{\circ} \mathrm{C}$. The finding that ATP levels do not fall to zero in the virulent strains is consistent with the finding that they must be shifted to somewhat higher temperatures $\left(41^{\circ}\right.$ and $43^{\circ} \mathrm{C}$ for G184A and G222B, respectively) to completely uncouple oxidative phosphorylation.

Respiration rates. The effects of different temperature shifts on respiration rates parallel their effects on oxidative phosphorylation and ATP levels. As shown in Fig. $7 \mathrm{~A}$, the rate of decline in respiration rates of the Downs strain is less rapid at $34^{\circ} \mathrm{C}$ than at $37^{\circ} \mathrm{C}$, and respiration rates fall to only $40 \%$ of initial levels. Respiration rates begin to increase 9-10 d after the temperature shift, about when yeasts appear in the cultures.

When G184A and G222B were shifted to a higher temperature $\left(40^{\circ} \mathrm{C}\right)$, the patterns of change in respiration rates more closely resemble that in Downs strain shifted to $37^{\circ} \mathrm{C}$ (Fig. $7 \mathrm{~B}$ ). It is particularly striking that when shifted to higher temperatures, both virulent strains show an extended dormant phase in which spontaneous respiration rates fall to zero. The decrease in respiration in response to the temperature elevation to $40^{\circ} \mathrm{C}$ appears to be more rapid in G184A than in G222B.

Electron transport components. Table II shows that the changes in concentrations of mitochondrial electron transport components in Downs shifted to $34^{\circ} \mathrm{C}$ are moderated compared with those when the strain is shifted to $37^{\circ} \mathrm{C}$. The level of cytochrome $a a_{3}$ decreased to $66 \%$ of the initial level; cytochrome $b$ to $\sim 42 \%$ of the initial level; and cytochrome $c$ fell to $46 \%$. At the same time, the changes in the more virulent strains shifted to $40^{\circ} \mathrm{C}$ are similar to those in the Downs strain shifted to $37^{\circ} \mathrm{C}$. In particular, cytochromes $c$ and $a a_{3}$ are not detectable spectrophotometrically during stage 2 of the transition and cytochrome $b$ falls to $\sim 10 \%$ of the initial levels.

\section{Rate of growth of yeast phase cells as a function of temperature}

Downs, G184A, and G222B showed parallel differences in $\mathrm{LD}_{50} \mathrm{~S}$ for mice when tested as either early mycelial transformants or yeast phase cells. If pathogenicity is related to temperature sensitivity, then yeast phase cells of the three strains should show the same relative sensitivity to high temperatures as cells passing through the mycelial to yeast transition. To test this prediction, we obtained growth curves of yeast cells of the three strains at different temperatures (Fig. 8). At $35^{\circ} \mathrm{C}$ (Fig. $8 \mathrm{~A}$ ), the curves for all three strains were indistinguishable and the doubling times were $13.5 \mathrm{~h}$. At $37^{\circ} \mathrm{C}$ (Fig. $8 \mathrm{~B}$ ), the curves for G222B and G184A remained indistinguishable, with doubling times of 13 h. However, Downs yeast showed a longer lag phase and a decreased growth rate (doubling time of $16.5 \mathrm{~h}$ ) compared with the other strains. At $39^{\circ} \mathrm{C}$ (Fig. $8 \mathrm{C}$ ), the differences between Downs and the more virulent strains were even more pronounced. There was a longer lag period and a further decrease in growth rate (doubling time of Downs was $24 \mathrm{~h}$ compared with $13.5 \mathrm{~h}$ for G184A and G222B). The growth yield of Downs at the stationary phase was also significantly less than for G184A and G222B. At $41^{\circ} \mathrm{C}$ (Fig. $8 \mathrm{D}$ ), Downs did not grow at all. The other two strains continued to grow, but the rate of growth for 


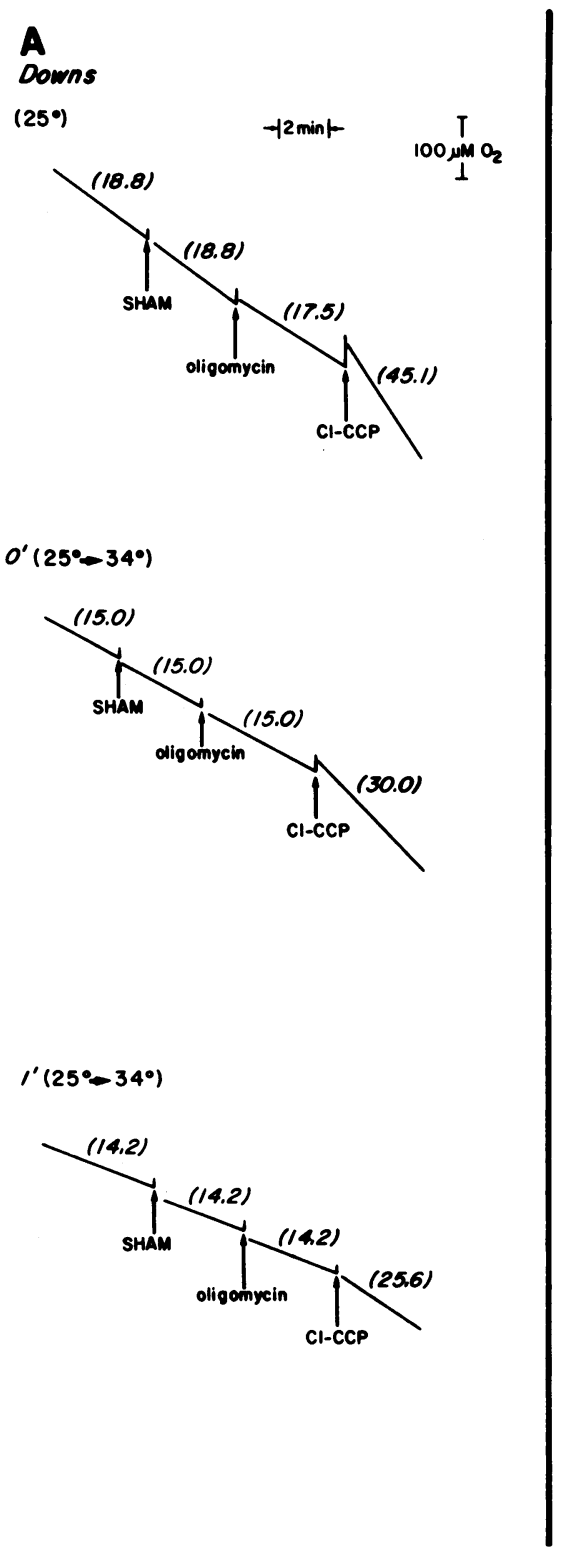

Figure 5. Oxygen electrode recordings of respiration of mycelial cells at $25^{\circ} \mathrm{C}$, immediately after $(0)$ and $1 \mathrm{~min}$ after shift up in temperature. The procedures were the same as for Fig. 1. $(A)$ Downs; $(B)$ $\mathrm{G} 184 \mathrm{~A}$; and $(C) \mathrm{G} 222 \mathrm{~B}$. The values in parentheses are rates of oxygen consumption (microliters of $\mathrm{O}_{2}$ per hour per milligram dry weight).

G184A (doubling time of $33 \mathrm{~h}$ ) was substantially slower than for G222B (doubling time of $30 \mathrm{~h}$ ). G222B also grew to a higher cell number than G184A. These experiments were repeated three times on separate cultures with essentially the same results.

\section{Discussion}

The present work shows that the patterns of physiological changes during the mycelial to yeast transitions of more virulent strains of $H$. capsulatum are fundamentally similar to those previously reported for the less virulent Downs strain. In all cases, the triggering event appears to be a heat-related insult induced by the temperature shift up. The temperature shift leads to declines in ATP levels, respiration rates, and concentrations of electron transport components (stage 1). The cells then enter a stage of lower metabolic activity (stage 2), and finally recover and trans-
C

6222

(25\%)

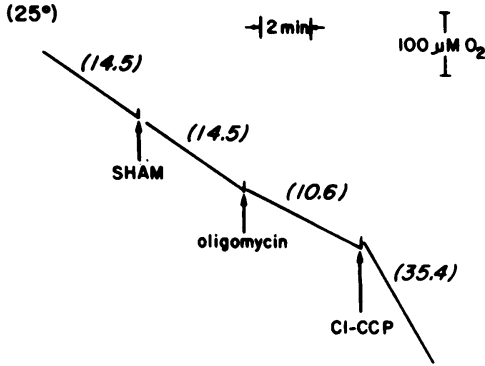

$\left.0^{\prime}(258-43)^{\circ}\right)$

(19.0)

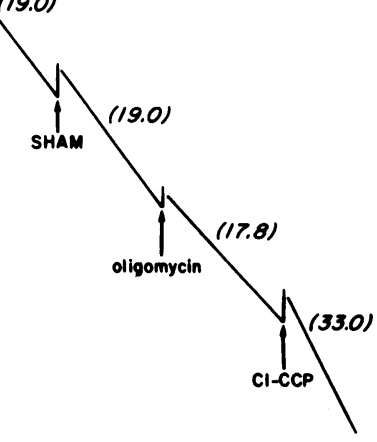

$l^{\prime}\left(25^{\circ}-43^{\circ}\right)$

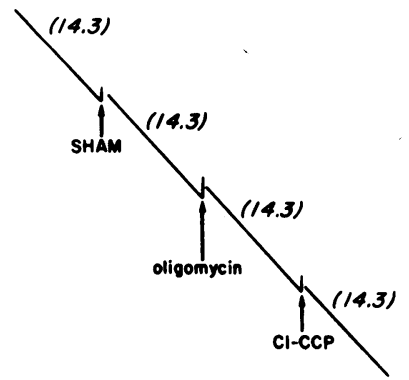

Additions were oligomycin $(5 \mu \mathrm{g} / \mathrm{ml})$ and Cl-CCP $(0.5 \mathrm{mM})$. Salicylhydroxamic acid $(0.2 \mathrm{mM})$ was added to inhibit the alternate oxidase. The experiment was repeated six times with independent cultures and essentially identical results were obtained.

form to yeast morphology (stage 3), presumably reflecting adaptation to growth at higher temperatures.

Our results show further that a major difference between the more virulent strains and the Downs strain is that the former are more resistant to temperature shifts. When the temperature is shifted from $25^{\circ}$ to $37^{\circ} \mathrm{C}$, as is ordinarily done to induce the morphological transitions, changes in ATP levels, respiration rates, and electron transport components are more severe in the Downs strain than in the virulent strains. The morphological transition of the Downs strain can be made to resemble those of the more virulent strains simply by shifting it to a lower temperature $\left(34^{\circ} \mathrm{C}\right)$. At the same time, the morphological transitions of the more virulent strains can be made to resemble that of the Downs strain by shifting them to higher temperatures $\left(40^{\circ}-\right.$ $43^{\circ} \mathrm{C}$ ). We note also that $\mathrm{G} 184 \mathrm{~A}$ is more sensitive to elevated 

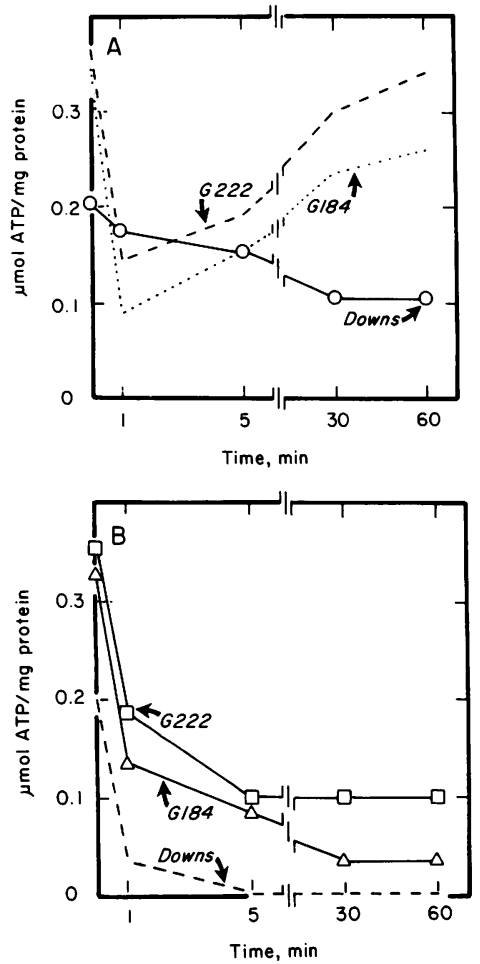

Figure 6. Effect of temperature shifts on intracellular ATP levels. The procedures were the same as for Fig. 2. (A) The Downs culture was shifted from $25^{\circ}$ to $34^{\circ} \mathrm{C}$. ATP levels for G184A and G222B shifted from $25^{\circ}$ to $37^{\circ}$ (Fig. 2) are indicated by dashed lines for comparison. $(B)$ The G222B and G184A culture were shifted from $25^{\circ}$ to $40^{\circ} \mathrm{C}$. ATP levels for the Downs strain shifted from $25^{\circ}$ to $37^{\circ} \mathrm{C}$ (Fig. 2) are indicated by dashed lines for comparison.

temperature than G222B. This difference is as predicted from the relative $L_{50}$ s of $G 184 A$ and $G 222 B$.

The difference in temperature sensitivity of the three strains can be correlated with the temperature required for complete uncoupling of oxidative phosphorylation: $37^{\circ} \mathrm{C}$ in the Downs strain, $41^{\circ} \mathrm{C}$ in $\mathrm{G} 184 \mathrm{~A}$, and $43^{\circ} \mathrm{C}$ in $\mathrm{G} 222 \mathrm{~B}$. When the morphological transitions occur at lower temperatures, $34^{\circ} \mathrm{C}$ for Downs and $37^{\circ} \mathrm{C}$ for G184A and G222B, respiration is partially uncoupled, which is judged by the degree to which respiration is stimulated by $\mathrm{Cl}-\mathrm{CCP}$. Considered together, these findings suggest that partial or complete uncoupling of oxidative phosphorylation is an early event and very possibly the primary event in the morphological transition in all three strains. Although uncoupling of oxidative phosphorylation is by itself sufficient to account for the decline in ATP levels in stage 1 of the transition, our results leave open the possibility that other heat-related insults contribute to this decline.

The differences in temperature required for uncoupling of oxidative phosphorylation could reflect differences in lipid or
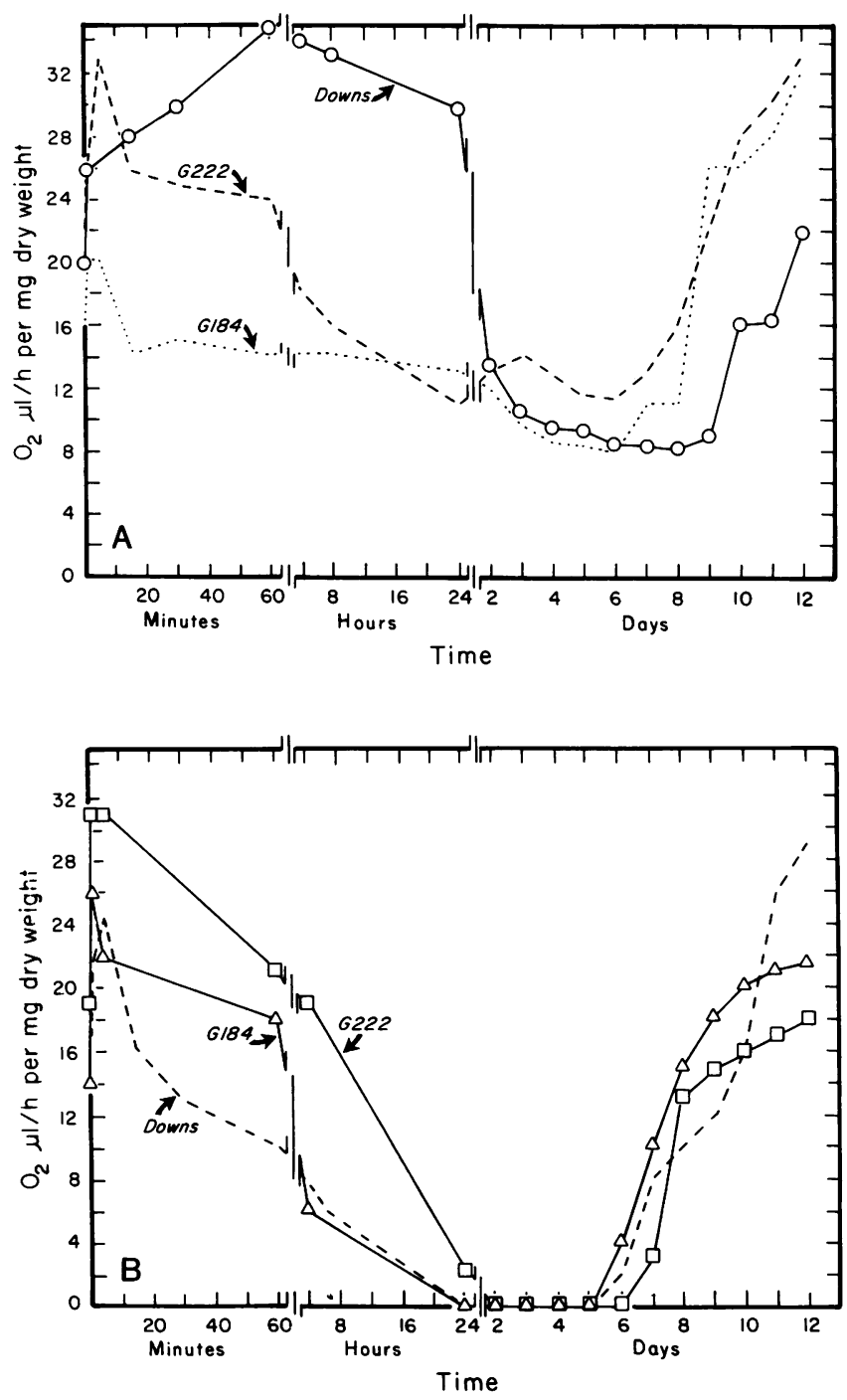

Figure 7. Respiration rates at various points during the mycelial to yeast phase transition. The experiment was initiated by shifting mycelia from $25^{\circ}$ to $34^{\circ}$ to $40^{\circ} \mathrm{C}$. The procedures were the same as for Fig. 3. $(A)$ The solid line shows respiration rates of Downs strain obtained at various times after temperature shift from $25^{\circ}$ to $34^{\circ} \mathrm{C}$. The dashed lines are the respiration rates of G184A and G222B shifted from $25^{\circ}$ to $37^{\circ} \mathrm{C}$. These are transcribed from Fig. 3. $(B)$ The solid lines are respiration rates of $\mathrm{G} 184 \mathrm{~A}$ and $\mathrm{G} 222 \mathrm{~B}$ switched from $25^{\circ}$ to $40^{\circ} \mathrm{C}$. The dashed line shows respiration rates of the Downs strain after the switch from $25^{\circ}$ to $37^{\circ} \mathrm{C}$. These are transcribed from Fig. 3.

Table II. Concentrations of Cytochromes in Mitochondria Isolated from Transforming Cells after Temperature Shifts from the $25^{\circ}-34^{\circ} \mathrm{C}$ (Downs) or the $25^{\circ}-40^{\circ} \mathrm{C}(\mathrm{G} 184 \mathrm{~A}$ and G222B)*

\begin{tabular}{|c|c|c|c|c|c|c|c|c|c|}
\hline \multirow[b]{2}{*}{ Days } & \multicolumn{3}{|l|}{ Downs } & \multicolumn{3}{|l|}{ G184A } & \multicolumn{3}{|l|}{ G222B } \\
\hline & cyt $a a_{3}$ & cyt $b$ & cyt $c$ & cyt $a a_{3}$ & cyt $b$ & cyt $c$ & cyt $a a_{3}$ & cyt $b$ & cyt $c$ \\
\hline 0 & 0.15 & 0.26 & 0.13 & 0.23 & 0.20 & 0.16 & 0.16 & 0.26 & 0.19 \\
\hline 1 & 0.07 & 0.11 & 0.06 & $\mathrm{ND} \ddagger$ & 0.06 & 0.04 & ND & 0.03 & ND \\
\hline 2 & 0.10 & 0.16 & 0.10 & ND & 0.04 & ND & ND & 0.03 & ND \\
\hline 3 & 0.10 & 0.15 & 0.11 & ND & 0.02 & ND & ND & 0.02 & ND \\
\hline 12 & 0.22 & 0.20 & 0.14 & 0.07 & 0.15 & 0.10 & 0.10 & 0.19 & 0.12 \\
\hline
\end{tabular}

cyt, cytochrome. * Cytochrome concentrations were calculated from low temperature difference spectra of dithionite-reduced minus oxidized mitochondria. The values are expressed as nanomoles per milligram mitochondrial protein. $\ddagger N D$, nondetectable. 

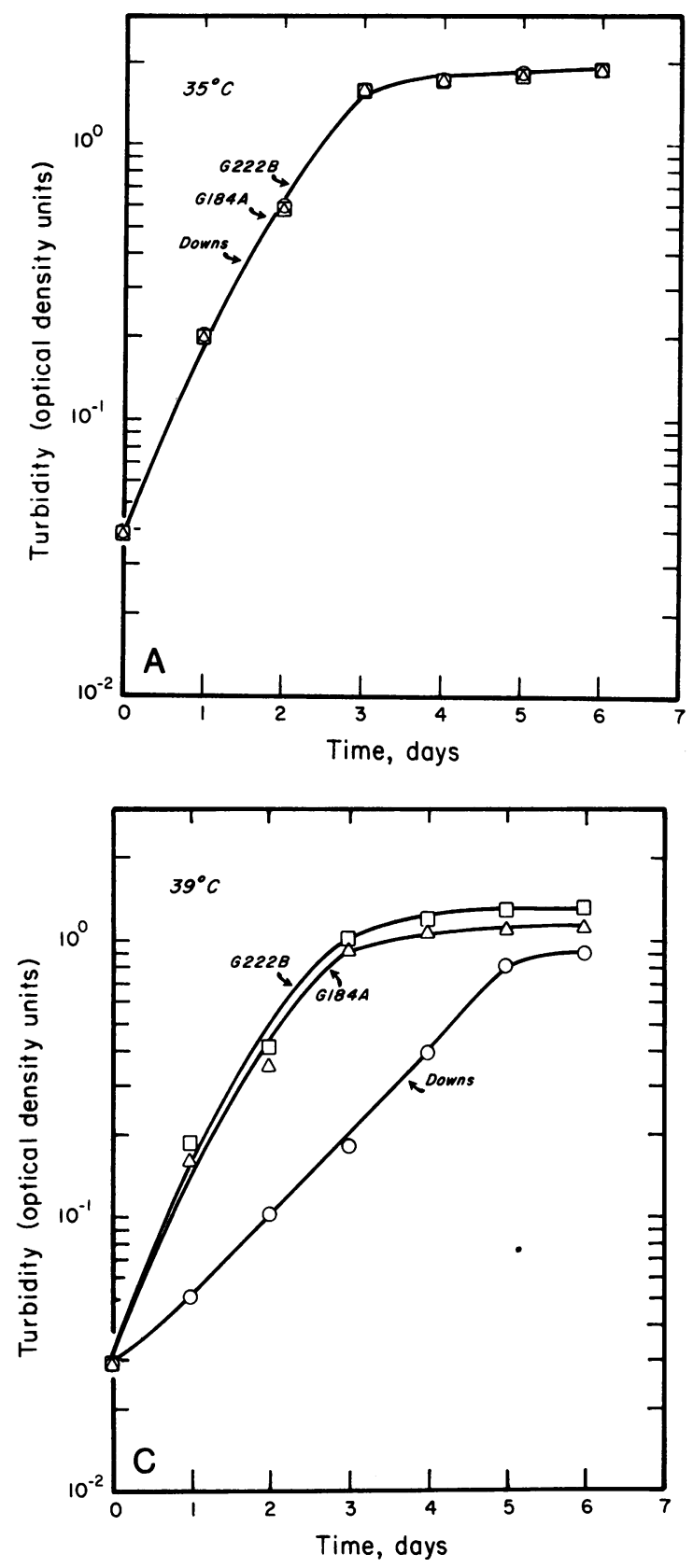

Figure 8. Growth curves of Downs, G184A, and G222B yeast cells at $35^{\circ} \mathrm{C}(A), 37^{\circ} \mathrm{C}(B), 39^{\circ} \mathrm{C}(C)$, and $41^{\circ} \mathrm{C}(D)$. Initial innocula of 1 $\times 10^{6}$ cells $/ \mathrm{ml}$ for each of the cultures were obtained by appropriate dilutions of growing cultures. Cell densities were quantitated by hemacytometer counts and optical density readings at $650 \mathrm{~nm}$ with a Bausch

protein compositions of mitochondrial membranes in the strains, or more specific differences in the composition of the ATP synthetase complex. The strain differences among the strains might also be specified by a small number of nuclear and/or mitochondrial genes, since digest patterns of messenger transfer DNA and ribosomal DNA of each of the strains used in our study show that they belong to a different class (15). In the yeast form of the Downs strain, respiration is tightly coupled to oxidative phosphorylation at $37^{\circ} \mathrm{C}$. Therefore, the mycelial to yeast transition must include some alteration in the mitochondrial membrane or ATP synthetase complex that permits respiration to remain coupled at $37^{\circ} \mathrm{C}$.
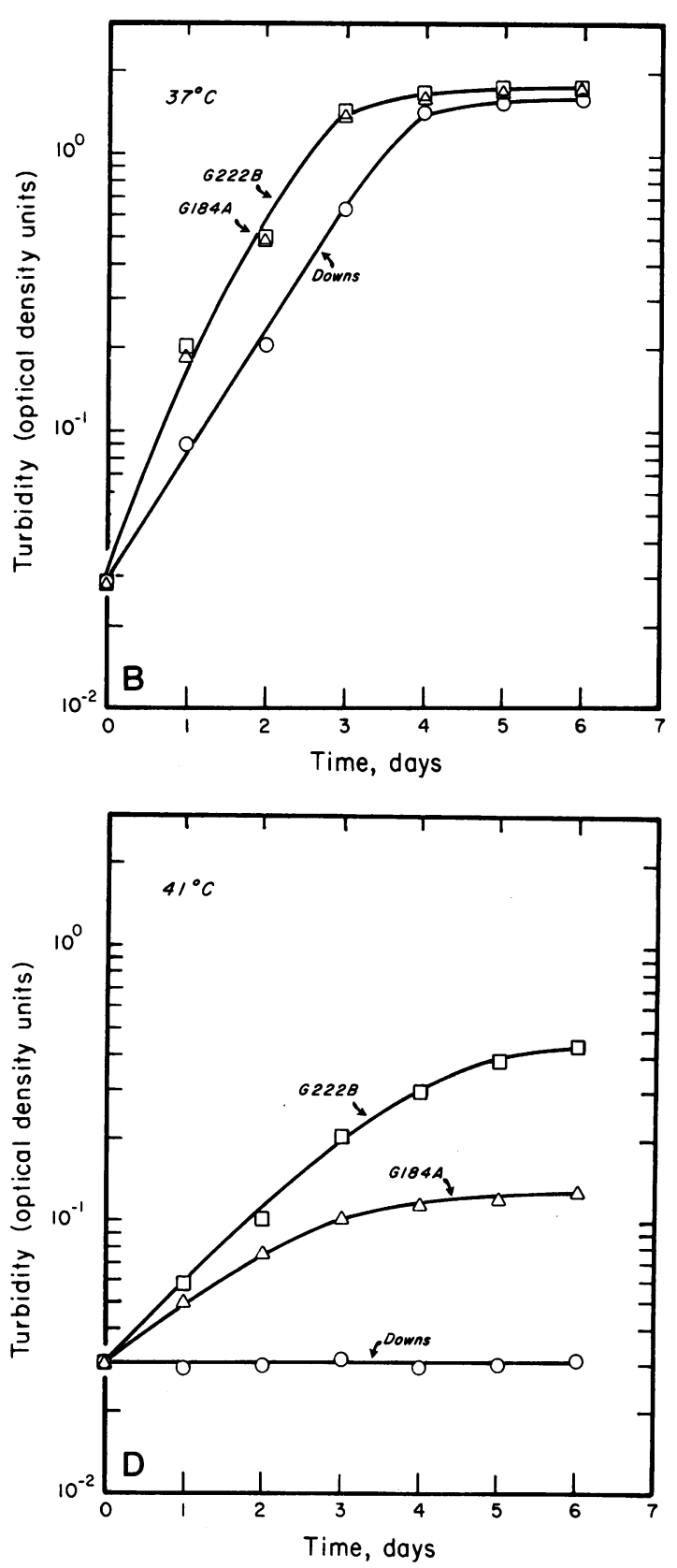

and Lomb-Spectronic 20. 0.4 OD U on the ordinate scale in the linear portion of the growth curve corresponds to $3.2 \times 10^{6} \mathrm{cells} / \mathrm{ml}$. These experiments were repeated three times on different cultures with essentially the same results.

When mycelia of Downs are incubated at $37^{\circ} \mathrm{C}$ the transition is prolonged, and cysteine or other suylfhydryl groups are required for survival (4). Previous studies with the Downs strain showed that cysteine is required during stage 2 for the operation of shunt pathways which permit electron transport to bypass inhibited portions of the cytochrome system. These shunt pathways appear to depend upon residual cytochrome oxidase, which appears to be present below levels that can be detected spectrophotometrically. In contrast, mycelia of G184A and G222B transform rapidly at $37^{\circ} \mathrm{C}$ and do not require any cysteine or other sulfhydryls in the medium for survival at this temperature. However, when the temperature is raised to $40^{\circ}-43^{\circ} \mathrm{C}$, these 
strains become dependent on cysteine-activated shunt pathways during stage 2 (our unpublished observations). The results for the more virulent strains show that cysteine is required to complete the transition only under conditions in which electron transport components are severely depleted. Therefore, it is likely that the primary, if not the only function of cysteine in stage 2 of the transition, is to activate the respiratory shunt pathways.

We previously pointed out that there may be a relationship between temperature shifts that trigger the morphological transition and heat shock (7). Heat shock proteins are induced in all the strains in response to temperature shifts (16). These proteins may contribute to the survival of the organism after the initial temperature shift. It seems unlikely that heat shock proteins per se are directly involved in morphogenesis. However, it is possible that heat shock proteins and morphogenic proteins are under similar control and are induced in parallel early in the transition. An intriguing possibility is that proteins which function in morphogenesis have heat shock promoters.

Recently, Van Der Ploeg and co-workers (17) have reported that a heat shock response also occurs after the transfer of the parasitic protozoa Trypanosoma brucei and Leishmania major from the temperature of their poikilothermic insect vectors $\left(25^{\circ} \mathrm{C}\right)$ to that of their homeothermic mammalian host $\left(37^{\circ} \mathrm{C}\right)$. This may be another example of a differentiation process involved in pathogenicity that is triggered by a temperature shift and resultant heat shock response.

The mycelial phase of $H$. capsulatum is the normal morphology for growth in soil (1). It has been proposed that only the yeast phase is pathogenic (18). This hypothesis is supported by the histopathology of the disease, in which only the yeast phase is seen inside of macrophages in infected tissues. More recent experiments in our laboratory showing that inhibition of the mycelial to yeast transition by $p$-chloromercuriphenylsulfonic acid renders the virulent strains nonpathogenic for mice provide stronger evidence that only the yeast phase is pathogenic (our unpublished observations). Because conversion to the yeast phase appears to be required for progressive infection, it is likely that the rapidity and efficiency of the transformation and/or the subsequent growth of the yeast phase are important determinants of virulence. This conclusion is supported by the correlation we observed between sensitivity to elevated temperature of the mycelial and yeast phases and virulence for mice of all three of the strains we used in our experiments. Therefore, the hypothesis that a heat-related insult is a common element in the mycelial to yeast transition, and that the efficiency of the transformation and subsequent growth of yeast depend on the sensitivity to elevated temperatures of all three strains provides an explanation for the low level of virulence of the Downs strain of $H$. capsulatum and the difference in virulence between G184A and G222B. Note that our results leave open the possibility that temperature sensitivity and pathogenicity are not causally related to each other (our unpublished observations), but are both controlled by a third factor (e.g., membrane lipids).

The normal body temperature of mice is between $37^{\circ}$ and $38.1^{\circ} \mathrm{C}(19)$, sufficient to exploit the differences in the transition and growth of yeast among the strains. We would predict that all three $H$. capsulatum strains would be less virulent at higher body temperatures. The resistance of birds, which have a body temperature $>40^{\circ} \mathrm{C}$, to $H$. capsulatum infection supports this notion. In the same way, the Downs strain should be more virulent in a host with a body temperature below $37^{\circ} \mathrm{C}$.

Our work also suggests a possible strategy to develop effective live vaccines for infections with dimorphic fungi. Infection with temperature-sensitive mutants that are similar to the Downs strain might provide the most effective protection against infection with the lowest chance of toxicity.

\section{Acknowledgments}

These studies were supported by funds provided by the National Institutes of Health (grants AI-16228, AI-07172, and AI-07015), Progetto Finalizzato "Malattie da infezione," Decreto CNR (74388), and Contrato from "Commission des Communautes Europennes (TSD.M.018I) (SB).

\section{References}

1. Ajello, L., E. W. Chick, and L. Furcolow. 1971. Histoplasmosis. Proc. Natl. Conf., 2nd, Springfield, IL.

2. Schwartz, J., 1981. Histoplasmosis. Praeger Publishers, New York.

3. Cheung, S. C., G. S. Kobayashi, D. Schlessinger, and G. Medoff. 1974. RNA metabolism during morphogenesis in Histoplasma capsulatum. J. Gen. Microbiol. 82:301-307.

4. Maresca, B., A. M. Lambowitz, B. V. Kumar, G. Grant, G. S. Kobayashi, and G. Medoff. 1981. Role of cysteine in regulating morphogenesis and mitochondrial activity in the dimorphic fungus Histoplasma capsulatum. Proc. Natl. Acad. Sci. USA. 78:4596-4600.

5. Sacco, M., G. Medoff, A. Lambowitz, B. V. Kumar, G. S. Kobayashi, and A. Painter. 1983. Sulfhydryl induced respiratory "shunt" pathways and their role in morphogenesis in the fungus Histoplasma capsulatum. J. Biol. Chem. 258:8223-8230.

6. Kumar, B. V., B. Maresca, G. Medoff, and G. S. Kobayashi. 1983. Purification and properties of yeast specific cysteine oxidase from Histoplasma capsulatum. Biochemistry. 22:762-768.

7. Lambowitz, A. M., G. S. Kobayashi, A. Painter, and G. Medoff. 1983. Possible relationship of morphogenesis in the pathogenic fungus, Histoplasma capsulatum to heat shock response. Nature (Lond.). 303: 806-808.

8. Burt, W. E., A. L. Underwood, and G. L. Appleton. 1981. Hydroxamic acid from Histoplasma capsulatum that displays growth factor activity. Appl. Environ. Microbiol. 42:560-563.

9. Reed, L. J., and H. Muench. 1938. A simple method for estimating fifty percent end points. Am. J. Hyg. 27:493-497.

10. Lambowitz, A. M., and C. W. Slayman. 1971. Cyanide-resistant respiration in Neurospora crassa. J. Bacteriol. 108:1087-1096.

11. Kornberg, A. 1955. Adenosine phosphokinase. In Methods in Enzymology. Vol. II. S. P. Colowick and N. O. Kaplan, editors. Academic Press, Inc., New York. 495-500.

12. Lowry, O. H., N. J. Rosebrough, A. L. Farr, and R. J. Randall. 1951. J. Biol. Chem. 193: 265-275.

13. Lardy, H. A., D. Johnson, and W. C. McMurray. 1958. Antibiotics as tools for metabolic studies. I. A survey of toxic antibiotics in respiratory, phosphorylative and glycolytic systems. Arch. Biochem. Biophys. 78:587589.

14. Slater, E. C. 1967. Application of inhibitors and uncouplers for a study of oxidative phosphorylation. In Methods in Enzymology. Vol. 10. R. W. Estabrook and M. E. Pullman, editors. Academic Press, Inc., New York. 47-48.

15. Vincent, R. D., R. Goewert, W. E. Goldman, G. S. Kobayashi, A. Lambowitz, and G. Medoff. 1986. Classification of Histoplasma capsulatum isolates by restriction fragment polymorphisms. J. Bacteriol. 165:813-818.

16. Shearer, G., C. Birge, G. Kobayashi, and G. Medoff. 1985. Heat shock proteins in temperature induced phase transitions of Histoplasma capsulatum and Blastomyces dermatitidis. Ann. Meet. Am. Soc. Microbiol., Abst. F64. 375.

17. Van der Ploeg, L. H. T., S. H. Giannini, and C. R. Cantor. 1985. Heat shock genes: regulatory role for differentiation in parasitic protozoa. Science (Wash. DC). 228:1443-1446.

18. Scherr, G. H., and J. W. Rippon. 1959. Experimental histoplasmosis in cold-blooded animals. Mycopath. Mycol. Appl. 11:241-249.

19. Jackson Laboratory Staff. 1975. Biology of the Laboratory Mouse. Dover Publishers, New York. 337-350. 